\title{
O USO DAS PARLENDAS NA TERAPIA COMUNITÁRIA INTEGRATIVA
}

\author{
THE USE OF PARLENDS IN INTEGRATING COMMUNITY THERAPY
}

\author{
Doralice Oliveira GOMES ${ }^{1}$ \\ Nair Meneses dos SANTOS ${ }^{2}$
}

RESUMO: O estudo objetivou refletir sobre o uso das parlendas na Terapia Comunitária Integrativa (TCI). As parlendas integram a cultura popular e são versinhos com rima fácil que tratam de temas infantis, envolvendo, muitas vezes, a associação entre o recitar e o expressar-se corporalmente. Trata-se de um estudo qualitativo, realizado por meio da revisão de literatura, e da descrição do uso de parlendas em dois grupos de Terapia Comunitária Integrativa no Distrito Federal, no período de 2015 a 2016. O estudo sinaliza que o uso das parlendas nas rodas de TCI evidenciou a importância da valorização da identidade cultural como estratégia terapêutica, contribuindo para o acolhimento dos participantes, entrosamento, fortalecimento de vínculos, diminuição da tensão, possibilidades de ressignificar os problemas e superar vivências de sofrimento.

PALAVRAS CHAVE: Parlendas. Cultura popular. Terapia comunitária integrativa. Músicas infantis.

ABSTRACT: The study aimed to reflect on the use of the parliaments in Integrative Community Therapy (TCI). The parliaments integrate popular culture and are verses with easy rhyme that deal with children's issues, often involving the association between reciting and expressing oneself. This is a qualitative study, carried out through the literature review, and the description of the use of speeches in two groups of Integrative Community Therapy in the Federal District, from 2015 to 2016. The study indicates that the use of TCI's team highlighted the importance of the valorization of cultural identity as a therapeutic strategy, contributing to the reception of participants, networking, strengthening of ties, reduction of tension, possibilities to re-characterize problems and overcome experiences of suffering.

KEYWORDS: Recitative elements. Popular culture. Integrative community therapy. Children's songs.

\footnotetext{
${ }^{1}$ Mestre em Saúde da Família pela Universidade Federal do Ceará - UFC. Terapeuta Comunitária e Coordenadora Técnica de Terapia Comunitária Integrativa na Gerência de Práticas Integrativas em Saúde da Secretaria de Estado de Saúde do Distrito Federal. E-mail: doralice32@hotmail.com

${ }^{2}$ Licenciada em Letras Português pela Universidade Federal de Uberlândia. Terapeuta Comunitária e Assistente Social no Hospital São Mateus (Cruzeiro-DF) e no Centro de Referência em Direitos Humanos do Distrito Federal. Presidente da Instituição Espaço Urucum-Arteterapia. E-mail: nairmeneses@gmail.com
} 


\section{Introdução}

Ai, eu entrei na roda Ai, eu não sei como se dança $A i$, eu entrei na 'rodadança' Ai, eu não sei dançar. (Cantiga popular)

A cultura de um povo é resultante da criação humana e envolve comportamentos, conhecimentos, língua, crenças, manifestações artísticas, leis, regras, costumes, técnicas de transformação da natureza, isto é, o modo de vida de cada sociedade (NOVA, 2011). Por meio da cultura pode-se regular a convivência e a comunicação em sociedade. A cultura é compreendida como um estilo de vida próprio que caracteriza uma sociedade, e que possibilita às pessoas que compartilham da mesma cultura possuírem uma identidade cultural. A identidade cultural é o que lhes assegura o senso de pertencer a uma coletividade (OLIVEIRA, 2005).

Há uma transmissão desses saberes culturais de geração a geração por meio do convívio social, que possibilita que as pessoas criem, expressem, transmitam, recebam e transformem sua cultura (NOVA, 2011). A cultura é dinâmica, está em constante mudança, modificando-se no decorrer do processo sócio-histórico. É um movimento dialético entre a permanência das tradições e o enriquecimento do patrimônio cultural à luz das demandas da atualidade.

No presente artigo foi dado destaque a uma parte da cultura, denominada cultura popular. A cultura popular surge do cotidiano, das tradições e costumes e é transmitida transgeracionalmente, principalmente de forma oral, possuindo por característica a permanência de padrões tradicionais (OLIVEIRA, 2005).

A cultura popular é originada de criações anônimas do povo, como as parlendas, cantigas de roda e de ninar; e, também, de autores conhecidos, a exemplo da literatura de cordel e xilogravuras. Todavia, embora tenha por característica proeminente a permanência, a cultura popular também é uma realidade viva, sendo reinventada pela criatividade das pessoas, num misto de conservação e inovação (NOVA, 2012).

A cultura popular brasileira é fruto da miscigenação de culturas, com destaque para a portuguesa, africana e indígena; abrangendo literaturas, provérbios, parlendas, lendas folclóricas, cantigas de roda, músicas de ninar, mitos, tradições, dentre outras.

Das manifestações culturais presentes no Brasil, o presente artigo dedicar-se-á às parlendas e suas possibilidades de contribuição nas rodas de Terapia Comunitária 
Integrativa (TCI), sendo a TCI uma abordagem de saúde comunitária que tem por princípio o reconhecimento e valorização das diferentes fontes de saber, sejam saberes de cunho científico ou popular. Na TCI, a diversidade cultural é um recurso reconhecido, valorizado e mobilizado na busca de resolução de problemas coerentes com as necessidades e realidades culturais das comunidades (GOMES, 2013).

\section{Parlendas}

As parlendas são versinhos com rima fácil que tratam de temas infantis, sendo denominadas por poesia-brinquedo, pois estão nas brincadeiras de crianças, envolvendo, muitas vezes, a associação entre o recitar e o expressar-se corporalmente (SOARES; SILVA, 2009). As rimas e conteúdos de fácil assimilação favorecem a popularidade das parlendas entre as crianças, sendo utilizadas em jogos, como recurso para melhoria do relacionamento interpessoal, para diversão ou no processo pedagógico formal.

As parlendas estão presentes também no universo adulto por remeter às suas próprias memórias da infância e podem contribuir na relação adulto-criança. Elas divertem e ensinam, sendo consideradas recurso lúdico-pedagógico. É comum, em especial em cidades interioranas, que os pais brinquem com seus filhos utilizando as parlendas (SALVADOR, 2007). Em geral, os adultos transmitem às crianças as histórias, canções e brincadeiras que mais gostavam quando eles mesmos eram crianças (GIRARDELLO, 2007 apud NATERA, 2011).

Segundo o ilustre folclorista Luís da Câmara Cascudo, grande parte das parlendas origina-se na cultura europeia, tendo sido trazidas pelos portugueses. Foram incorporadas à cultura brasileira e modificadas no novo contexto cultural (SOARES; SILVA, 2009). À herança musical dos portugueses foram agregados elementos africanos, ameríndios, italianos, alemães, espanhóis, franceses, ingleses, americanos, japoneses, sírios, libaneses, turcos, judeus, poloneses e holandeses, o que tornou a cultura brasileira ainda mais rica e diversificada (BRAGA; FERNANDES, 1970).

Embora as parlendas tenham em si a tradição que é transmitida transgeracionalmente, são modificadas ao longo do tempo. Em especial as crianças, que mais as utilizam no cotidiano de suas brincadeiras, as reinventam e fazem adaptações baseadas em seu próprio vocabulário e experiências. Tem-se um "círculo de contribuições populares anônimas" (SOARES; SILVA, 2009, p. 35). Interessante 
assinalar que embora as parlendas sofram transformações ao serem adequadas a cada contexto histórico, normalmente mantém sua essência (BRAGA; FERNANDES, 1970).

As parlendas fazem parte da cultura popular, integrando a tradição dos brasileiros. Muitas parlendas foram criadas há décadas, sendo a maior parte de autoria desconhecida (SOARES; SILVA, 2009). Como são de origem popular, podem ser criadas por qualquer pessoa, podendo variar e serem conhecidas de modo diferente. Uma mesma parlenda pode possuir várias versões (SALVADOR, 2007).

Cascudo (1984 apud SALVADOR, 2007, p. 14-15) classifica as parlendas em brincos e mnemônicas. Brincos “[...] são os primeiros e ingênuos mimos infantis, agrados carinhosos que os pais, babás usam (ditas e recitadas) para entreter ou aquietar as crianças". Na parlenda a seguir, tem-se um exemplo de parlenda brinco. A brincadeira que fala do carneirinho envolve pegar a mão da criança e balançá-la até a criança sorrir. Após isso, quem está brincando com a criança dá uma batida de leve numa parte do corpo da criança.

\author{
Marra-marra, Carneirinho, \\ Marra-marra, Carneirinho. \\ Mão-mole, Mão-mole, \\ Quem sorri há de apanhar \\ (Cantiga popular)
}

Outra classificação são as mnemômicas, sendo;

[...] ditas ou recitadas pelas crianças para enganar e principalmente com a finalidade de memorizar nomes, números e outros conteúdos. Não se altera, é usada em áreas diversas com simplicidade para ensinar a contar, a brincar, a marchar, é muito útil na educação. (CASCUDO, 1984, p.14 apud SALVADOR, 2007, p. 15).

Esse tipo de parlenda pode ser exemplificada por:

Um, dois,

Feijão com arroz;

Três, quatro,

Arroz com pato;

Cinco, seis,

Bolo inglês;

Sete, oito,

Café com biscoito;

Nove, dez,

Vai na bica lavar os pés

Pra comprar cinco pastéis

Pra ganhar 500 réis, 


\title{
Pra comer no dia dez \\ (Cantiga popular)
}

Outras características marcantes nas parlendas são a musicalidade e o humor, que, também, contribuem para sua aceitação não só por crianças, mas, também, por adultos e idosos (SALVADOR, 2007). O bom humor e a leveza podem ser ilustrados na parlenda que fala de uma casinha com cupins.

Fui morar numa casinha-nha

Infestada de cupim-pim-pim

Saiu de lá-lá-lá uma lagartixa-xa

Olhou pra mim olhou pra mim

E fez assim: hum! Hum!

(Cantiga popular)

As temáticas das parlendas giram em torno de temas simples, a exemplo da vida na área rural, os animais, a família, as regiões e cidades do país, meios de transporte, atividades do cotidiano.

Corre cutia, na casa da tia.

Corre cipó, na casa da avó.

Lencinho na mão, caiu no chão.

Moça bonita, do meu coração...

Um, dois, três!

(Cantiga popular)

As parlendas têm por vezes características de fábula, ao atribuírem atributos humanos aos animais, como na parlenda em que o macaco faz compras ou a borboleta cozinha.

\author{
O macaco foi à feira \\ Não teve o que comprar \\ Comprou uma cadeira \\ Pra comadre se sentar \\ A comadre se sentou \\ A cadeira esborrachou \\ Coitada da comadre \\ Foi parar no corredor. \\ (Cantiga popular) \\ Borboletinha tá na cozinha \\ Fazendo chocolate \\ Para a madrinha \\ Poti-poti, perna de pau \\ Olho de vidro \\ E nariz de pica-pau, pau, pau. \\ (Cantiga popular)
}


As parlendas fazem parte da cultura brasileira e representam uma relevante tradição cultural no Brasil, sendo consideradas, por vezes, tesouros da poesia popular. É fundamental para a identidade do país a valorização de sua cultura, uma vez que a cultura de um povo o caracteriza, possibilita às pessoas possuírem uma identidade cultural e, consequentemente, um senso de pertencer a uma coletividade (OLIVEIRA, 2005).

\section{Terapia comunitária integrativa: espaço de valorização da cultura}

O trem maluco Quando sai de Pernambuco Vai fazendo chic, chic Até chegar no Ceará. Rebola, bola Você diz que dá, que dá Você diz que dá na bola Na bola você não dá.

(Cantiga popular)

A parlenda utilizada na abertura dessa seção é uma homenagem ao criador da Terapia Comunitária Integrativa, Prof. Dr. Adalberto Barreto, etnopsiquiatra cearense, que com sua visão sensível à sua própria história de vida, enquanto sertanejo e cientista, desenvolveu a abordagem da TCI, tendo na Antropologia Cultural um dos seus aportes teóricos. Nas palavras de Barreto (2008, p. 235): "Na Terapia Comunitária, a cura passa pelo resgate das raízes e dos valores culturais que despertam no homem o valor e o sentido de pertencer".

A biografia de Adalberto Barreto está narrada no livro $O$ índio que vive em mim: o itinerário de um psiquiatra brasileiro (BARRETO; BOYER, 2003) e sintetizada no prefácio do livro Terapia Comunitária Integrativa Passo a Passo (BARRETO, 2008).

A Terapia Comunitária Integrativa (TCI) tem sua origem na inquietude vivenciada por Adalberto Barreto, ao confrontar sua formação como médico com as suas origens familiares sertanejas, alicerçadas na religiosidade popular. Em seu livro autobiográfico, Adalberto questiona se os saberes acadêmicos e populares são excludentes, ou seja, se para um existir o outro deveria ser desconsiderado. Diante desse impasse, ele se propôs o desafio de fazer coabitar em si universos aparentemente contraditórios, o acadêmico e o popular, que considerava complementares e que lhe 
proporcionavam conhecer o homem na sua totalidade, e criou a TCI sob essas bases (GOMES, 2013).

A Terapia Comunitária Integrativa (TCI) é uma abordagem de atenção à saúde comunitária, criada pelo Prof. Dr. Adalberto Barreto, da Universidade Federal do Ceará. É uma prática de grupo desenvolvida desde 1987, no Pirambu, bairro de periferia do município de Fortaleza, no Estado do Ceará. A TCI incentiva, por meio de encontros comunitários, a expressão de experiências de vida, possibilitando que as dificuldades vivenciadas no cotidiano possam ser compartilhadas, bem como as estratégias de superação que foram desenvolvidas. Considera que qualquer pessoa, independentemente da sua condição social, econômica e cultural, possui recursos e saberes úteis a si e aos outros (BARRETO, 2008).

Os objetivos da TCI, segundo Barreto (2008, p. 39), são:

1) Reforçar a dinâmica interna de cada indivíduo;

2) Reforçar a autoestima individual e coletiva;

3) Redescobrir a confiança em cada indivíduo, diante de sua capacidade de evoluir e de se desenvolver como pessoa;

4) Valorizar o papel da família e da rede de relações que ela estabelece com seu meio;

5) Suscitar, em cada pessoa, família ou grupo social, seu sentimento de união e identificação com seus valores culturais;

6) Favorecer o desenvolvimento comunitário, prevenindo e combatendo as situações de desintegração dos indivíduos e das famílias, através da restauração e fortalecimento dos laços sociais;

7) Promover e valorizar as instituições e práticas culturais tradicionais que são detentoras do saber fazer e guardiãs da identidade cultural;

8) Tornar possível a comunicação entre as diferentes formas do saber popular e saber científico;

9) Estimular a participação como requisito fundamental para dinamizar as relações sociais, promovendo a conscientização e estimulando o grupo, através do diálogo e da reflexão, a tomar iniciativas e ser agente de sua transformação.

Os aspectos teóricos que estavam subjacentes à prática foram identificados por Adalberto Barreto, à medida que sistematizava a TCI nos encontros com a comunidade. Barreto (2008) identificou cinco bases teóricas que alicerçam a TCI: pensamento sistêmico, teoria da comunicação, antropologia cultural, resiliência e pedagogia de Paulo Freire.

As bases teóricas listadas têm seus saberes inter-relacionados. No presente artigo daremos destaque à Antropologia Cultural.

A valorização da cultura configura-se como um dos elementos estruturantes dessa abordagem. Os encontros visam despertar a dimensão terapêutica do grupo, 
valorizando a herança cultural dos antepassados, que no caso do Brasil está na ancestralidade indígena, africana, europeia e oriental, ou seja, a multicultura brasileira, e do saber produzido pela experiência de vida dos participantes (BARRETO, 2008).

Para a antropologia cultural, as pessoas são resultantes de suas crenças, costumes, mitos, valores, rituais, religião, língua, e do que fazem a partir de sua história de vida. Há um referencial histórico e sociocultural na construção da identidade individual e coletiva. A partir da cultura se desenvolvem habilidades e competências para pensar, avaliar, discernir valores e fazer opções no cotidiano. Com base na identidade individual e coletiva, as pessoas podem se afirmar, se aceitar, assumir uma identidade como cidadãos, romper com relações de dominação e exclusão social pautadas em culturas que desvalorizam outras. A diversidade cultural é rica de fonte de saberes, sendo um recurso a ser reconhecido, valorizado e mobilizado na busca de resolução de problemas coerentes com as necessidades e realidades culturais das comunidades (MARCONI; PRESOTTO, 2008).

Para Barreto (2008), a antropologia cultural estima os valores culturais como fatores importantes para a formação da identidade do indivíduo e do grupo, área que subsidia a edificação das redes sociais que incluem ações intersetoriais, interinstitucionais, valorização dos recursos locais, fortalecimento de vínculos e apoio à dinâmica familiar. Na Terapia Comunitária Integrativa, o reconhecimento e a valorização dos saberes e crenças populares são fundamentais para que as pessoas estejam ativas, fortalecidas, no processo de transformação de sua história (BARRETO, 2008).

\title{
A roda de terapia comunitária integrativa
}

\author{
Ô pião entrou na roda \\ $\hat{O}$ pião \\ Ô pião entrou na roda \\ $\hat{O}$ pião \\ Roda pião, bambeia pião \\ Roda pião, bambeia pião \\ (Cantiga popular)
}

A prática da TCI é realizada num encontro em que as pessoas acomodam-se numa configuração de roda, uma vez que os participantes sentam-se em círculo para que o encontro terapêutico aconteça. Trata-se de um encontro coordenado por um terapeuta 
comunitário e um coterapeuta, pessoas habilitadas por uma formação específica em TCI para desempenhar essa função, que ficarão responsáveis por conduzir, ou facilitar, o encontro (SOUZA et al, 2011).

A TCI possui uma metodologia bem definida, sendo conduzida em etapas e seguindo regras de convivência que possibilitam que o encontro ocorra de forma respeitosa e com seu potencial promotor de saúde e fomentador de redes sociais solidárias otimizado. As etapas de uma roda de TCI são: acolhimento, escolha do tema, contextualização, problematização, ritual de conotação positiva e avaliação (BARRETO, 2008; CAMAROTTI; GOMES, 2009).

No acolhimento, os terapeutas buscam contribuir para que todos os participantes estejam bem acomodados, sentados em círculo, de modo que seja possível uma escuta respeitosa e um maior entrosamento do grupo. Nessa etapa, o terapeuta explica o que é a TCI, apresenta as regras, comemoram-se os aniversários e as datas importantes para os participantes e realiza-se uma dinâmica de entrosamento.

\section{Regras de participação na terapia comunitária integrativa:}

As regras são muito importantes na TCI. O espaço é público e, em geral, os grupos são abertos. O estabelecimento de regras mínimas entre os participantes é primordial para que seja estabelecido um ambiente de cuidado mútuo e de partilha:

- Silêncio: Regra de "ouro" na TC. Escutar atentamente quando uma pessoa do grupo está falando permite acolher, respeitar e, posteriormente, contribuir com a pessoa e o grupo.

- Falar na primeira pessoa: Cada um fala na primeira pessoa $(\mathrm{Eu})$, fala da sua experiência.

- Não fazer discursos, sermões e julgamentos: em geral é uma postura que desqualifica o outro e que não deve ser utilizada, pois o objetivo é a partilha de experiências, o que estimula a criação e o fortalecimento de vínculos saudáveis.

- Recursos culturais: músicas, poesias, ditados populares, piadas são muito bem vindos, pois podem proporcionar acolhimento, momento de descontração, ressignificação da situação vivida e senso de pertença (CAMAROTTI; GOMES, 2009, p. 221).

Após o acolhimento, tem-se o momento da escolha do tema, quando os participantes apresentam algo que esteja gerando sofrimento ou outro assunto que queiram compartilhar, e o tema é democraticamente escolhido. Em seguida, o proponente do tema expõe sua vivência com maior detalhamento e o grupo pode fazer- 
lhe perguntas que contribuam para ampliar sua compreensão. Essa etapa é chamada de contextualização.

A contextualização finaliza no momento em que o terapeuta apresenta ao grupo uma questão gerada com o aprofundamento do tema escolhido. A pergunta básica é “Quem já viveu uma situação parecida e o que fez para superá-la?” Nessa etapa da problematização, os participantes falam de suas vivências relacionadas ao tema do encontro.

A etapa seguinte constitui-se do momento em que os participantes compartilham os aprendizados pela participação na roda, a partir da escuta das histórias de vida. É a etapa da conotação positiva.

Por fim, a equipe responsável pela roda faz a apreciação do encontro. Nesse momento somente a equipe participa e avalia quais pontos foram realizados com êxito e quais pretendem aprimorar nos próximos encontros, bem como as providências necessárias.

\section{Parlendas nas rodas de TCI}

A infância é algo precioso [...] a cultura popular é uma segunda infância. (HORTÉLIO, 2008, p. 28 apud NATERA, 2011, p. 39)

A TCI tem como dois fundamentos a perspectiva de que a primeira escola é a família em que se nasce e o primeiro mestre a criança que se foi. Ambos constituem quem se é e tem uma grande influência no modo de cada pessoa ver e viver a vida. Faz parte da formação em TCI um aprofundamento nesses fundamentos, por meio de vivências específicas, como o 'resgate da criança interior' e 'trabalhando a integração do masculino e feminino' (CAIFCOM, 2017).

A citação abaixo apresenta o relato de uma terapeuta comunitária em formação. O depoimento consta na Dissertação de Mestrado de Márcia Carísio (2010, p. 99), que abordou a Terapia Comunitária Integrativa como um encontro que transforma o jeito de ver e conduzir a vida. 
O resgate da criança está em mim, essa dinâmica até hoje fica no meu pensamento, nunca vai sair da gente. Cada coisa que a gente viveu. Eu vi minha criança, vi como ela foi feliz. A gente se descobriu, pelo menos, sei que fui uma criança feliz. Hoje eu posso trazer essa criança para junto de mim de novo. É muito bom.

Segundo Zago (2017), o resgate da criança interior é um dos elementos mais importantes do trabalho terapêutico, pois contribui no processo de autoconhecimento de todo ser humano. A autora destaca que na criança interior estão tanto lembranças ruins, os traumas, como também as lembranças alegres. Destaca a importância de o adulto brincar, pois quando brinca acessa a criança, que é sua maior fonte de criatividade e inspiração. O objetivo desse resgate não é infantilizar o adulto, mas lembrá-lo do espírito lúdico, livre, que está mais presente nas crianças. Zago (2017) exemplifica algumas perguntas que podem ajudar o adulto nesse processo de acalentar a criança que foi: Você se lembra do seu brinquedo preferido quando criança? Por onde aquele sentimento de alegria, espontaneidade, ânsia de crescer?

$\mathrm{Na}$ TCI, o brincar faz parte do encontro terapêutico, as falas podem ser ilustradas por músicas, provérbios, parlendas ou piadas que tenham afinidade com o que esteja sendo compartilhado. Em especial na etapa de aquecimento é indicada uma atividade lúdica que possua música, gestos e movimentos e motivem as pessoas a interagirem, abraçarem-se, olharem-se. Esta atividade pode contribuir para a descontração e entrosamento do grupo, sendo recomendável que o próprio grupo proponha uma atividade lúdica (BARRETO, 2008).

Reflexões realizadas em estudo sobre a inserção da música nos encontros de TCI podem ser transpostas para o uso específico das parlendas neste mesmo contexto. Fix, Leite e Galvani (2007, p. 452) apresentam as funções da música nas rodas de TCI:

\begin{abstract}
Acolher no grupo; aquecimento [...] acolher a dor; celebrar a alegria; catalisar as falas do grupo; função de continência; função de espelho; estimular a capacidade de resiliência; ressignificação; propiciar a sensação de pertencimento e inclusão (no grupo e na comunidade) [...] Durante a fala [...] qualquer pessoa do grupo pode interromper com uma música, provérbio, [parlenda], ou uma piada que tenha a ver com o tema que está sendo exposto.
\end{abstract}

A espontaneidade que é natural na criança, em geral, não é no adulto, o que pode gerar tensão e constrangimento ao serem propostas atividades lúdicas durante as rodas de TCI, a exemplo do uso das parlendas. Os padrões rígidos da vida adulta culminam 
por esconder a criança que vive nele. Estudos realizados sobre o uso de atividades lúdicas na TCI apontaram para uma elevação da autoestima dos participantes e ressignificação de conflitos (ARVATI; CURZIO, 2007).

As parlendas possibilitam a presença do humor nas rodas de TCI. Barreto (2007) apud Silva (2010) ressalta a importância do humor no encontro terapêutico, pois trazer a dimensão lúdica ao trágico possibilita aos participantes rirem e aprenderem, mas com respeito e leveza. O ambiente mais leve pode ampliar e diversificar a visão sob um mesmo fato, possibilitando, também, novas formas de resolução e alívio.

Pesquisa realizada por Oliveira e Ferreira Filha (2011) sobre a contribuição dos recursos culturais para a Terapia Comunitária Integrativa na visão do terapeuta identificou que os recursos culturais resgatam e fortalecem valores e vínculos, evidenciam a identidade pessoal e social dos indivíduos, ajudam a pessoa a ressignificar seu sofrimento e facilitam a participação no encontro. As autoras da pesquisa ressaltam que os recursos culturais dependem do tipo de comunidade e da idade dos participantes, além de outros fatores próprios de cada realidade.

\section{Retratos do cotidiano: o uso das parlendas em rodas de TCI na cidade satélite do Itapoã/DF e em um hospital privado na cidade satélite do Cruzeiro/DF}

O presente artigo teve como motivação o uso das parlendas nas rodas de TCI realizadas com idosos na cidade satélite Itapoã, e com os funcionários do hospital privado, cidade satélite do Cruzeiro, ambas no Distrito Federal. As rodas foram realizadas nos anos de 2015 e 2016, com uma média de 15 participantes por encontro, sob a coordenação das terapeutas comunitárias Nair Meneses, Iolanda Santos e Regina Melo.

As parlendas estavam presentes em todas as etapas da roda, desde o convite para as mesmas. Foram entregues convites escritos utilizando parlendas adaptadas para a TCI, a exemplo da parlenda que segue:

$$
\begin{aligned}
& \text { Seja bem-vindo olelê... } \\
& \text { Seja bem-vinda olalá } \\
& \text { Venha pra terapia } \\
& \text { venha parlendear } \\
& \text { Terapia com parlendas } \\
& \text { pra tristeza afugentar. } \\
& \text { (Cantiga popular) }
\end{aligned}
$$


No acolhimento do grupo, chás de ervas comumente utilizadas pelas comunidades eram disponibilizados, a exemplo do chá de alecrim, que ao ser degustado estimulava o resgate dos saberes tradicionais na saúde, e estimulava o grupo a compartilhar vivências pessoais no uso medicinal e social das ervas. Tal experiência era associada com as parlendas. No caso do Alecrim cantava-se a parlenda:

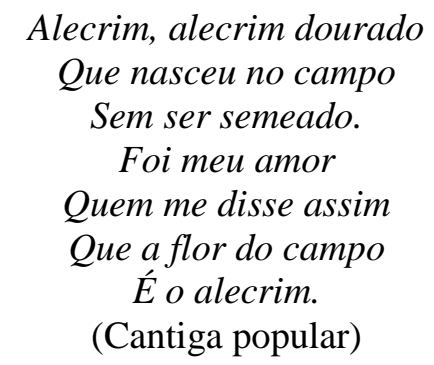

As rodas aconteciam aos domingos, o que motivava a utilização da parlenda:

Hoje é domingo
Pé de cachimbo
o cachimbo é de barro
Bate no jarro
o jarro é de ouro
Bate no touro
O jarro é de ouro
Bate no Touro
O touro é valente
Bate na gente
A gente é fraco
Cai no buraco
O buraco é fundo
Acabou-se o mundo.
(Cantiga popular)

Os nomes dos participantes também foram fontes de inspiração para cantarem parlendas e assim homenageá-los, contribuir para o fortalecimento de sua autoestima pelo acolhimento, valorização de suas histórias e do bom humor. A senhora Terezinha foi uma das contempladas pelo grupo.

\footnotetext{
Terezinha de Jesus

De uma queda, foi ao chão

Acudiram três cavalheiros

Todos os três, chapéu na mão

O primeiro foi seu pai

O segundo, seu irmão

O terceiro foi aquele

Que a Tereza deu a mão
} 
Terezinha levantou-se

Levantou-se lá do chão

E sorrindo disse ao noivo

Eu te dou meu coração

Da laranja, quero um gomo

Do limão, quero um pedaço

Da morena mais bonita

Quero um beijo e um abraço.

(Cantiga popular)

No decorrer da TCI havia histórias que abordavam vivências de sofrimento, a exemplo de uma briga de casal. Nesses momentos, uma das opções de parlenda era:

$$
\begin{gathered}
\text { O cravo brigou com a rosa } \\
\text { Debaixo de uma sacada } \\
\text { O cravo saiu ferido } \\
\text { E a rosa, despedaçada. } \\
\text { O cravo ficou doente } \\
\text { A rosa foi visitar } \\
\text { O cravo teve um desmaio } \\
\text { A rosa pôs-se a chorar. } \\
\text { (Cantiga popular) }
\end{gathered}
$$

Questões sociais eram trazidas e algumas parlendas davam suporte e puderam acolher a temática por meio dos recursos culturais. Se alguém se queixava de aspectos financeiros, uma canção comumente utilizada pelo grupo era:

$$
\begin{gathered}
\text { Eu sou pobre, pobre, pobre, } \\
\text { De marré, marré, marré. } \\
\text { Eu sou pobre, pobre, pobre, } \\
\text { De marrédeci. } \\
\text { Eu sou rica, rica, rica, } \\
\text { De marré, marré, marré. } \\
\text { Eu sou rica, rica, rica, } \\
\text { De marrédeci. } \\
\text { (Cantiga popular) }
\end{gathered}
$$

Nas situações em que a pergunta “[...] alguém tem algum problema ou algo que está lhe tirando o sono?" era seguida de um longo silêncio, cantava-se.

O sapo não lava o pé

Não lava porque não quer

Ele mora lá na lagoa

Não lava o pé porque não quer.

(Cantiga popular) 
Espontaneamente os participantes relacionavam as parlendas com experiências das suas histórias de vida, evidenciando a potência dos recursos culturais na valorização da identidade cultural das pessoas e como estratégia terapêutica. Numa das rodas em que cantou-se a parlenda 'Capelinha de melão', uma participante compartilhou com o grupo que sua mãe utilizava a fruta como purgante natural. Em outra oportunidade compartilhou-se sobre o consumo da batata doce inspirado na parlenda: " $O$ doce perguntou pro doce qual é o doce mais doce que o doce de batata doce? O doce respondeu pro doce que o doce mais doce que o doce de batata doce é o doce de batata doce".

No repertório cultural da TCI encontram-se músicas, provérbios e parlendas adaptadas para a TCI. São adaptações simples, objetivas, facilmente assimiladas pelo grupo (MARTINS et al., 2007).

Como pode o peixe vivo viver fora d'água fria? Como pode o peixe vivo viver fora d'água fria? Como poderei viver? Como poderei viver? Sem a minha, sem a tua, sem a nossa terapia? (Cantiga popular adaptada para a TCI))

As experiências do uso das parlendas nos grupos do Itapoã e do Cruzeiro no DF foram de grande importância para a realização das rodas, tendo como foco o resgate e valorização da cultura popular. $\mathrm{O}$ uso das parlendas proporcionou momentos de descontração, relaxamento e entrosamento do grupo, expresso, muitas vezes, por boas risadas coletivas.

\section{Considerações finais}

O estudo sobre o uso da parlendas nas rodas de TCI possibilitou aprofundar a reflexão sobre a versatilidade destes saberes culturais enquanto contribuintes num encontro terapêutico. Trata-se de repertório de amplo conhecimento no contexto nacional, o que favorece a participação das pessoas, o fortalecimento dos vínculos, o entrosamento, o resgate e valorização da cultura popular e, consequentemente, da identidade cultural dos presentes. A oportunidade de utilizar as parlendas nas rodas de 
TCI proporcionou momentos de diversão, acolhimento e ressignificação de situações difíceis vivenciadas no cotidiano por meio da arte, do lúdico e do bom humor.

As parlendas constituem-se, portanto, num instrumento de fácil utilização nas rodas, cabendo aos terapeutas comunitários utilizarem o bom senso para que este recurso seja utilizado de forma leve, respeitosa e adequada ao contexto do grupo.

\section{REFERÊNCIAS}

ARVATI, F. Z.; CURZIO, E. A. C. R. D. Jogos e brincadeiras na Terapia Comunitária. Instrumentos para manutenção do aquecimento do grupo. Relato de Experiência. In.: GRANDESSO, M.; RIVALTA, M. C. B. Terapia comunitária integrativa. Tecendo redes para a transformação social. Saúde, educação e políticas públicas. São Paulo: Casa do Psicólogo, 2007.

BARRETO, A. Terapia comunitária integrativa passo a passo. Fortaleza: Gráfica LCR, 2008.

BARRETO, A.; BOYER, J. P. O índio que vive em mim: o itinerário de um psiquiatra brasileiro. São Paulo: Editora Terceira Margem, 2003.

BRAGA, H.; FERNANDES, R. Cancioneiro folclórico infantil. Rio de Janeiro: Ministério da Educação e Cultura, 1970.

CAIFCOM. Programação do curso de pós-graduação lato sensu em terapia comunitária integrativa. Centro de atendimento, ensino e pesquisa do indivíduo família e comunidade. Porto Alegre, 2017. Disponível em:

<http://www.caifcom.com.br/pos/index.php?pos=61>. Acesso em: 29 jan. 2016.

CANTIGAS POPULARES. Disponível em: <https://www.letras.mus.br/cantigaspopulares>. Acesso em: 29 jan. 2017.

CAMAROTTI, H.; GOMES, D. O. Terapia Comunitária Integrativa: circularidade nas relações sociais. In: OSÓRIO, L. C.; VALLE, M. E. P. (Orgs.). Manual de terapia familiar. Porto Alegre: Artmed, 2009.

CARÍCIO, M. R. Terapia comunitária: um encontro que transforma o jeito de ver e conduzir a vida. 2010. 133p. Dissertação de Mestrado. Mestrado em Enfermagem. Universidade Federal da Paraíba. João Pessoa, PB, 23 de fevereiro de 2010.

FIX, S. A. B.; LEITE, M. S. V.; GALVANI, C. Algumas reflexões sobre a inserção da música nos encontros de Terapia Comunitária no CEAF (Centro de Assistência à Família). In.: GRANDESSO, M.; RIVALTA, M. C. B. Terapia comunitária integrativa. Tecendo redes para a transformação social. Saúde, educação e políticas públicas. São Paulo: Casa do Psicólogo, 2007. 
GOMES, D. O. A expansão da terapia comunitária integrativa no Brasil e sua inserção em ações de políticas públicas nacionais. 2013. 154p. Dissertação de Mestrado. Mestrado Acadêmico em Saúde da Família. Universidade Federal do Ceará. Sobral, CE, 23 de agosto de 2013.

MARCONI, M. A.; PRESOTTO, Z. M. N. Antropologia: uma introdução. São Paulo: Atlas, 2008.

MARTINS, M. C. M. et al. Brincadeiras Cantadas. In.: GRANDESSO, M.; RIVALTA, M. C. B. Terapia comunitária integrativa. Tecendo redes para a transformação social. Saúde, educação e políticas públicas. São Paulo: Casa do Psicólogo, 2007.

NATERA, G. Brincadeira e música: orientações necessárias. Revista núcleo pedagógico de educação e arte: arte no campo, Florianópolis, v. 9, p. 35-50, 2011.

NOVA, S. V. Introdução à sociologia. São Paulo: Atlas, 2011.

OLIVEIRA, P. S. Introdução à sociologia. São Paulo: Editora Ática, 2005.

OLIVEIRA, D. S. T.; FERREIRA FILHA, M. O. Contribuição dos recursos culturais para a Terapia Comunitária Integrativa na visão do terapeuta. Revista Gaúcha de Enfermagem, v. 32, n. 3, Porto Alegre, set. 2011.

SALVADOR, Prefeitura Municipal de. Adivinhas, charadas, parlendas, provérbios e trava-línguas. Educação infantil/ciclos de aprendizagem I e II / educação de jovens e adultos. Prefeitura Municipal de Salvador. Salvador: 2007.

SILVA, M. R. G. A metáfora na linguagem da terapia comunitária: estudo de caso com pais de alunos do $1^{\circ}$ ciclo do Ensino Fundamental de uma Escola Municipal de Ipatinga - MG. 2010. 154p. Dissertação de Mestrado. Mestrado Acadêmico em Educação e Linguagem. Centro Universitário de Caratinga. Caratinga, MG, 10 de novembro de 2010.

SOARES, M. S.; SILVA, T. A. Literatura oral: as parlendas e o lúdico na escola. Revista de Letras, Artes e Comunicação. Blumenau, n. 1, v. 3, p. 31-43, jan/abr. 2009.

SOUZA, G. M. L.; SILVA, P. M. C.; AZEVEDO, E. B.; FERREIRA FILHA, M. O.; SILVA, V. C. L.; ESPINOLA, L. L. A contribuição da terapia comunitária no processo de saúde-doença. Cogitare Enfermagem, v. 16, n. 4, p. 682-688, 2011.

ZAGO, R. Entrevista sobre a importância da criança interior. Disponível em: $<$ http://www.somostodosum.com.br/artigos/autoconhecimento/entrevista-sobre-aimportancia-da-crianca-interior-14854.html>. Acesso em: 29 jan. 2016. 


\section{Como referenciar este artigo}

GOMES, Doralice Oliveira.; SANTOS, Nair Meneses dos. O uso das parlendas na terapia comunitária integrativa. Revista Temas em Educação e Saúde, Araraquara, v. 12, n. 2, p. 145-162, jul/dez. 2016. ISSN: 1517-7947.

Submetido em: 30/09/2016

Aprovado em: 30/11/2016 